\title{
Wellcome Trust sets out fresh misconduct standards
}

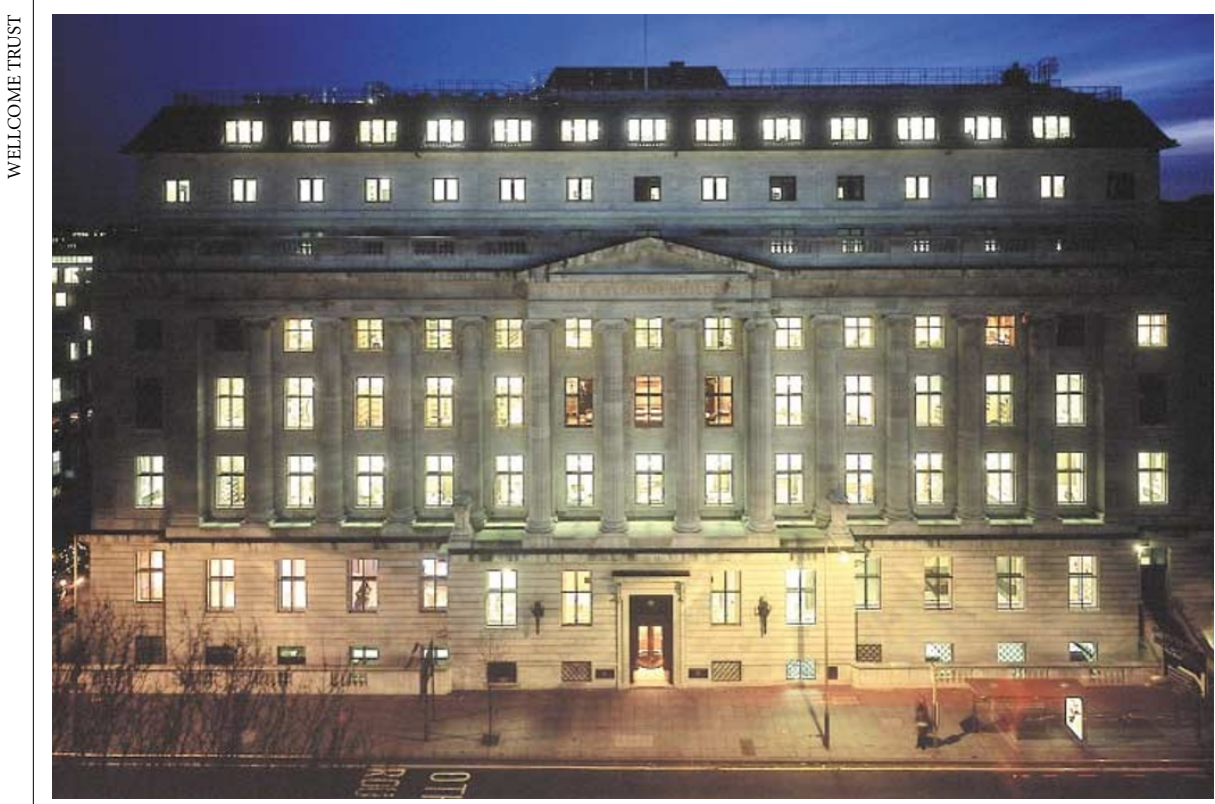

Standard bearer: the Wellcome Trust has released draft guidelines for handling scientific misconduct.

\section{Erica Klarreich, London}

Research institutes seeking grants from the Wellcome Trust will soon have to adhere to a new set of standards for scientific conduct. And in the absence of government action on research misconduct, observers say, the charitable trust's guidelines are likely to set a de facto standard for British universities.

A draft of the guidelines, issued for comment on 26 July, defines good science practice and sets out procedures for handling cases of misconduct, such as plagiarism and falsification of data. But in their current form, critics point out, they do little to protect people who blow the whistle on misconduct.

The trust, which funds nearly $20 \%$ of Britain's biomedical research, plans to insist that all institutions receiving its grants adhere to the standards from October 2002.

Robert Terry, a senior policy adviser at the trust, says the peer-review process cannot prevent scientific misconduct. "This issue has been discussed for a while in Britain, but hasn't moved much forward," he says. "We felt we had to make our own position clear."

The Medical Research Council, Britain's main publicly funded biomedical granting agency, expects institutions to investigate allegations concerning their own researchers. The Wellcome Trust says it will carry out its own investigations in "exceptional cases", such as when it feels its reputation is at stake.

The United Kingdom has no national body to investigate misconduct cases, and each of the six research councils, which distribute government grant money to scientists, has its own guidelines for universities.
"This is the biggest thing to happen in the field of scientific misconduct in the United Kingdom for years," says Drummond Rennie, deputy editor of the Journal of the American Medical Association and an expert on scientific misconduct in Europe. "I'm impressed by this document's decisiveness, thoughtfulness and clarity."

The extent of the Wellcome Trust's support for biomedical research is likely to turn its guidelines into de facto national guidelines, Rennie says. Terry agrees: "I doubt that universities will institute a system that only applies to Trust researchers," he says.

In December 2000, the European Science Foundation encouraged scientific societies to press for the creation of national bodies to investigate misconduct. Denmark is the only European nation that has such a body.

But Marcus De Ville, a spokesman for the UK Office of Science and Technology, says there are no plans to create one in Britain. "It is for the scientific body as a whole to regulate itself," he says. "The peer-review process is the system which verifies the credibility of scientific research, and that process works."

While broadly welcoming the guidelines, Herbert Arst, a professor of microbial genetics at Imperial College in London, says they offer inadequate protection to people who make allegations. Whistle-blowers are often stigmatized in the scientific community and may face expensive libel suits, he says, causing misconduct to go unreported.

Terry responds that the final Wellcome Trust guidelines may include stronger protection for whistle-blowers.
Academies called to task over human cloning débâcle

Laura Bonetta, Washington

The US National Academies has come under fire for inviting researchers who plan to clone human beings to a forum held in Washington on 7 August.

Severino Antinori, director of the International Associated Research Institute for Human Reproduction in Rome, and Panos Zavos, director of the Andrology Institute of America in Kentucky, used the meeting to announce plans to start cloning experiments in November. Television broadcasts subsequently led with the news in both the United States and Europe.

Also present was Brigitte Boisselier, scientific director of Clonaid, a company set up by the Raelian sect, which intends to clone humans.

"The academies should only have the best, most credible, and authoritative scientists to present data," argues David Mangus, a bioethicist at the University of Pennsylvania in Philadelphia.

Alan Trounson, deputy director of the Monash Institute of Reproduction and Development in Clayton, Australia, adds that media attention may help to "attract money and thereafter the skills to conduct this unfortunate experiment".

Debbie Stine, an academies official, defended the invitation, saying that the speakers had scientific credentials and both sides should be represented. But other participants say the would-be cloners gave no details of what they are doing, and no real dialogue took place.

There is also concern that the tidal wave of media coverage blurred the distinction between therapeutic cloning - which many scientists support - and reproductive cloning.

The forum was part of a fact-finding process for an academy panel that will report to Congress next month. The House of Representatives has passed a bill that bans human cloning, and the Senate will soon consider similar legislation.

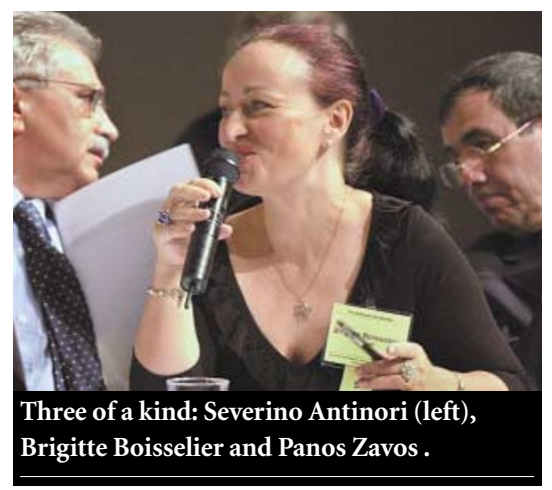

